Volume 3, No. 2, 2018

\author{
Widia Kusuma Wardani \\ received her Bachelor Degree at \\ English Language Education \\ Department of Universitas \\ Muhammadiyah Yogyakarta \\ (UMY). Widia is an \\ independent novice researcher \\ with research interests in \\ teaching and learning speaking \\ skills and the use of technology \\ in language learning. She is a \\ part time English teacher and \\ also a language consultant.
}

\section{The Characteristics of Anxious Students in Speaking Classroom}

\author{
Widia Kusuma Wardani \\ Universitas Muhammadiyah Yogyakarta \\ widiawardani17@gmail.com \\ DOI: https://doi.org/10.18196/ftl.3230
}

\begin{abstract}
This research investigates the characteristics (observable and non-observable) of anxious students in speaking classroom. This study was conducted in a private university in Yogyakarta, Indonesia. Two instruments were used in this study, namely structured observation and standardized open-ended interview. Two classes were observed. From the observation, four students were chosen to become the participants. This study found two symptoms which were divided into observable symptoms and non-observable symptoms. The observable symptoms were trembling, remaining silent, nervously touching object, stuttering or stammering, using filler, and getting sweaty. The non-observable symptoms were getting confused, getting cold, feeling nervous, and heart beating quickly.
\end{abstract}

Keywords: characteristics of anxious students, anxiety, speaking anxiety 
Introduction

In learning a language such as English, there are four skills studied by the students such as listening, reading, writing, and speaking. Those four skills are divided into two types, namely receptive skill and productive skill. Based on Brown (2000), listening and reading are categorized in receptive skills, and writing and speaking are categorized in productive skills. Speaking becomes an essential thing because one of the purposes of learning a language is to be able to use the language. One usage of the language is for oral communication. It is also a tool for communication with other people. In teaching and learning process, the English teachers often speak English in order to make the students accustomed to using English. Based on Dearden (2014), English as a medium of instruction has an important role in teaching and learning process, because it can help the students to get used to hearing the English words, and it can also improve the students' English ability especially speaking skill. In addition, English as a medium of instruction can motivate the students to learn the language (Ibrahim, 2001).

However, in speaking using English, the students also face some problems. One of the problems faced by the students is anxiety. Anxiety is a popular psychology phenomenon which is related to fear, selfesteem, and worry (Wu, 2010; Yahya, 2013; \& Zheng, 2008). According to Marwan (2008), anxiety can be defined as "threats to self-efficacy and appraisals of situations as threatening or an uneasy feeling due to something threatening" (p. 120). When students feel anxious about speaking, it can be indicated that they undergo speaking anxiety. According to Mak (2010), speaking anxiety will only take place when speaking is concerned. It can happen in the subject concerning speaking English. In addition, speaking anxiety can give a negative effect to the students (Liu, 2006; Mak, 2011). It can hinder the students to try to speak English, and in the end, it affects the students' speaking ability. Since speaking anxiety is one of the serious problems faced by the students, and it can affect negatively, speaking anxiety becomes an urgent thing to be studied. It is important to conduct research on speaking anxiety in order to find out the strategy to solve or reduce speaking anxiety.

Based on the limited observation done at English Language Education Department of a private university in Yogyakarta, Indonesia, speaking anxiety exists in English Foreign Language (EFL) classroom. During the teaching and learning 
process, the students also have to try to speak in English in the classroom in order to be able to interact with both the teachers and the other students. In some occasions, the teachers ask the students to do group discussion, presentation or role-play.

In doing group discussion, the students are asked to make a group of five, and the teacher gives some cases to the students. In the group, the students discuss the case with the group member using English. On another occasion, the teacher asks the students to do a presentation in front of the classroom. It can be done individually, in pair, or in a group. The teacher gives time for the students to prepare the material before doing the presentation. In addition, role play is also used in speaking classroom. The students are usually divided into some group or they can do the role play in pair. Before performing role-play, the students have time to make script and practice acting out.

Those speaking activities are done so that the students can practice speaking English. On the other hand, those speaking activities can cause anxiety among students. It happens because the students become the focus of attention. When the students do group discussion, presentation, or role-play, they are feared since they speak English in front of their classmates and lecturer (Liu,
2007). In addition, the students feel anxious, because they are afraid of making mistakes. Liu states that fear of making mistakes is one of the causes of speaking anxiety. Another cause of speaking anxiety is lack of practice. The students are anxious in speaking since they do not have plenty time to practice speaking English in their daily life, and they are not accustomed to speaking English in front of people (Anandari, 2015; Liu 2007).

Finally, this study was conducted in order to find out the characteristics of anxious students in speaking class. The characteristics or symptoms which were going to investigate were both observable and non-observable symptoms. Furthermore, this study is beneficial for English teachers. By reading this study, the teachers are able to identify which students undergo speaking anxiety, and from the results, they are also able to apply strategy in order to solve or reduce the students' speaking anxiety. This study also enriches the literature on language anxiety.

This study was conducted in a private university in Yogyakarta, Indonesia in its English Language Education Department. To collect the data, observation and interview were done. The observation was done at speaking subject, and four students became the participants in 
this study. This study investigates the answer to the question: What are the characteristics of anxious students in speaking classroom.

\section{Literature Review}

One of the famous phenomena which exist in foreign language classroom is anxiety. According to Wu (2010) and Zheng (2008), anxiety becomes a major problem in education field including in foreign language classroom and it needs to be overcome. Based on Marwan (2008), anxiety is defined as "threats to self-efficacy and appraisals of situations as threatening or an uneasy feeling due to something threatening" (p. 120). Additionally, Yahya (2013) mentions that anxiety is related to self-esteem, fear, and worry. Gregersen (2005) also states that students who are anxious in foreign language learning might not enjoy their learning. Thus, it can be concluded that anxiety is one of the problems exists in foreign language classroom which happens because of something threatening, and it needs to be solved. Anxiety must be overcome because it becomes an obstacle for the students, and it affects negatively to the students' ability. Aghani and Amanzadeh (2017) find that the correlation between students' anxiety and communication performance is strongly negative. Additionally, there is a negative correlation between language anxiety and achievement; if the anxiety increases, the achievement decreases (Awan, Azher, Anwar, \& Naz, 2010). Moreover, Lian and Budin (2010) also state that students who undergo high anxiety might think that second language learning is threatening, and they show poor performance as their response. Thus, it proves that anxiety affects negatively to students' performance.

The students can suffer anxiety in some occasions. One of the situations which can be a source of anxiety is when the students have to speak English. According to Tsiplakides and Keramedina (2009), many students are highly anxious to participate in speaking activities. In addition, Ahmed (2016) states that students feel anxious about speaking because they are afraid of being laughed by their classmates and they also worry if they fail their English class. If the students feel anxious in speaking English, it indicates that they undergo speaking anxiety. Based on Mak (2011), speaking anxiety can take place in a subject which focuses on speaking. In addition, Ahmed (2016) mentions that speaking anxiety is an obstacle for most learners, and it affects their speaking ability negatively. Therefore, it can be said that speaking anxiety only happens when speaking is concerned, and it becomes a serious 
problem for learners because of its negative effect. Liu (20016) finds that speaking anxiety affects negatively to student's speaking performance. The students who undergo speaking anxiety will get more difficulties in improving their speaking skill. In addition, speaking anxiety affects the students' attitude towards English language. According to Yahya (2013), anxiety affects students' behavior and their learning achievement; students also choose to not participate in speaking since they think that they are not good at speaking. The students who are anxious in speaking might tend to keep silent when they get a chance to speak English even when they like English. Finally, speaking anxiety needs to be solved.

When students feel anxious about speaking, they actually show some symptoms. The characteristics of anxious students are divided into two. The first is observable symptoms and the second is nonobservable symptoms. Observable symptoms mean that the symptoms can be seen by other people, but non-observable symptoms are the symptoms which are only felt by the anxious students. Based on Suleimenova (2013), anxious students show observable symptoms such as "squirming, playing with hair or clothing, nervously touching objects, stuttering or stammering" (pp. 1861-1862). In addition, anxious students also experienced getting sweaty, vomiting, trembling, and perspiring (Ansari, 2015; Boyce, Alber-Morgan, \& Riley, 2007). Hence, if the students show those symptoms when they speak English, it indicates that they undergo speaking anxiety.

Moreover, when students feel anxious, they do not only show observable symptoms, but they also feel non-observable symptoms. According to Suleimenova (2013), "fidgeting, headache, experiencing tight muscle, and feeling unexplained pain or tension in any part of the body" are experienced by the anxious students ( $\mathrm{p}$. 1861 - 1862). Ansari (2015) also states that "nervous, worried, fearful, and heartbeats quickly" (p. 39) is also felt by anxious students. Moreover, weak knees and dry mouth also become anxiety symptoms (Boyce, Alber-Morgan, \& Riley, 2007).

\section{Methodology}

Qualitative research method was adopted in this study. According to Creswell (2012), qualitative research allows the researcher to explore the problem by listening to the participants. Creswell also adds that the nature of qualitative study is the word. Hence, by applying qualitative research method, the data are detailed and rich. The method under qualitative used in 
this study was a case study. A case study was appropriate to be used since the problem investigated in this study was a specific problem. According to Merriam (1998), a case study is an investigation about "particular situation, event, program, or phenomenon" (p. 29). The kind of case study applied was an interpretive case study. Based on Merriam (1998), interpretive case study helps the researcher to get thick and rich data.

The instruments used in this study were observation and interview. A structured observation was done in order to get non-verbal data, and it was also used to choose the participants. According to Cohen, Manion, and Marrison (2011), in conducting structured observation, observation checklist must be prepared so that the observation will be organized.

Observation checklist contained the observable symptoms of speaking anxiety was prepared before conducting the observation. The researcher observed observable symptoms because those symptoms could be seen by other people. After preparing the observation checklist, the researcher asked permission to the lecturer who taught Listening and Speaking for Academic Purposes. The researcher chose this subject because this subject focused on speaking and had more speaking activities compared to the other subjects. The students participating in this study were freshmen. Two classes were observed. During the observations, the researcher was a complete observer meaning that the researcher only observes and is not a part of the group being observed (Cohen, Manion, \& Marrison, 2011). The researcher observed, recorded, and did note-taking. The observations were done twice for each classroom. The first observation was conducted when the students did a group discussion, and the second observation was done when the students did a presentation. After conducting the observations, the researcher analyzed the data by counting the frequencies. According to Cohen (2011), "for structured observations, researchers can count frequencies, and with references to an individual, group, classes, events, activities, behaviors and so on" (p. 464). After counting the frequencies, the students showing the observable symptoms more frequently than the other students became the participants in this research.

The second instrument used in this study was interview. Based on Cohen, Manion, and Marisson (2011), an interview is a verbal or non-verbal interaction between individuals, and it permits to get greater depth information than other methods. In addition, the type of interview used was a 
standardized open-ended interview. According to Cohen, Manion, and Marisson (2011), the characteristics of a standardized open-ended interview is the participants are asked the same basic questions using the same order. The interview was used to confirm the symptoms shown by the participants during the observations and to find out the non-observable symptoms. The researcher chose the participants by using the result of observations. The students showing the observable symptoms in the observations more often than the other students became the participants in this research. The participants were two female and two male students. Additionally, the researcher decided to do a phone interview, because one participant was in another city. In addition, the researcher got difficulty to meet the other three participants because they had assignments to do. After doing a phone interview, the researcher did some steps to analyze the data. The first step was transcribing the data where the researcher transformed the spoken data into written. The second step was member checking which was done to ensure that the data was the same as what the participant said during the interview. The third step was coding done in four ways which were open coding, analytical coding, axial coding, and selective coding.

\section{Findings}

The observations were done in two classes. The students were observed when they did group discussion and presentation in front of the class. There were seventeen observable symptoms presented in the table below. The observable symptoms were used to identify which students felt anxious in speaking class. The researcher only used observable symptoms, because those symptoms can be seen by other people. After doing the observations, the data was analyzed. The observation analysis presented below is the result of observations done in two classrooms. 
Table 1. The Observations Analysis

\begin{tabular}{|c|c|c|c|}
\hline No. & Visible symptoms & Frequency & Percentage \\
\hline 1. & Trembling & 13 & $8 \%$ \\
\hline 2. & Remaining silent & 25 & $15 \%$ \\
\hline 3. & Sitting in the back row & 0 & $0 \%$ \\
\hline 4. & Avoiding eye contact & 40 & $24 \%$ \\
\hline 5. & Squirming & 1 & $1 \%$ \\
\hline 6. & Playing with hair & 5 & $3 \%$ \\
\hline 7. & Playing with clothing & 20 & $12 \%$ \\
\hline 8. & Nervously touching object & 28 & $17 \%$ \\
\hline 9. & Stuttering or stammering & 7 & $4 \%$ \\
\hline 10. & Getting sweaty & 1 & $1 \%$ \\
\hline 11. & Vomiting & 0 & $0 \%$ \\
\hline 12. & Blushing & 0 & $0 \%$ \\
\hline 13. & Rubbing the palms & 14 & $8 \%$ \\
\hline 14. & Staggering voice & 3 & $2 \%$ \\
\hline 15. & $\begin{array}{l}\text { Reading from the script while giving a } \\
\text { presentation }\end{array}$ & 7 & $4 \%$ \\
\hline 16. & Too fast speed of speech & 1 & $1 \%$ \\
\hline 17. & Too slow speed of speech & 3 & $2 \%$ \\
\hline \multicolumn{2}{|r|}{ Total } & 168 & $100 \%$ \\
\hline
\end{tabular}

After doing the observations, the researcher chose four students to become the participants in this study. The participants were chosen because they showed observable symptoms more frequently than the other students. The result of the observations and the interview were triangulated. The findings were divided into observable symptoms and nonobservable symptoms.

Based on the observation result, some students were trembling when they spoke English. This symptom appeared thirteen times. It was seen when the students did a presentation in front of the classroom. They did the presentation using posters. 
While they were presenting, the poster was shaking too because they trembled. Two participants said that they trembled when they did the presentation in front of the classroom. When the researcher asked why the first participant trembled, the participant answered, "Because I am nervous if I speak in front of the classroom" (interview excerpt). While the third participant said, "Because I memorize what I am going to say, so I am afraid if I forget what I have to tell" (interview excerpt).

The second observable symptom shown by the students is remaining silent. It revealed 25 times. During the group discussion, some students only kept silent when the other students tried to tell their opinions. In one group which consisted of four up to five students, there was a student who kept silent while the other students in the same group were trying to tell their opinions. One of the participants kept silent during the group discussion and the presentation. Then the researcher asked why she remained silent in those two speaking activities. The first participant stated, "I am shy to speak because I have not known my friends well. I have prepared what I am going to say, but I am shy to speak in front of the classroom. I feel nervous, and I have a mixed feeling because they focus on me" (interview excerpt).
Nervously touching object symptom appeared 28 times during the observations. The students touched their book or their pen when they did a group discussion. One of the participants seemed nervously touching an object when he did a presentation in front of the classroom. He stated that he touched object nervously because he nervous when he did a presentation. On the other hand, participant two explained that she touched object such as pen in order to reduce her anxiety in speaking English especially when she did a presentation in front of the classroom.

The next observable symptom is stuttering or stammering. It revealed seven times during the first and the second observation. One of the students stuttered in the presentation. $\mathrm{He}$ said, "Homeschooling can help er er he or she, boy or girl, girl er because, because, er we can, we can'. Another student said, "Full-day school can er can, avoid, what, avoid, avoid". One of the participants stuttered when she spoke English especially when she did the presentation. The researcher asked her why she stuttered in the presentation, and she answered, "Because I have not been accustomed to do public speaking, and I am nervous. I also did not prepare well" (interview excerpt). 
Another characteristic which was appeared during the observation is getting sweaty. It revealed $1 \%$. It only happened in the second observation when the students did the presentation in front of the classroom. One participant in this research also said that he got sweaty when he spoke English in front of the class.

Using filler also became the characteristics of anxious students, though it was not listed in the observation checklist. During the observations, the researcher also took note to write something important. Based on the researcher's note-taking, some filler which was used by the students were "er" or "well". In the second observation, one student mumbled, "it's like er it's famous er and then er why we er". Two out of four participants mentioned that they used filler when they spoke English. The first participant and the second participant said that there was much filler when they spoke English.

Besides the observable symptoms, the participants in this study also mentioned some symptoms which finally categorized into non-observable symptoms. There are four non-observable symptoms mentioned by the participants. The first is getting confused. Participant four said that she was confused about what she has to say when she tried to speak English. The second non- observable symptom is getting cold. The second participant said that she would tremble and get cold when she was going to present something using English. In addition, three participants said that they felt nervous in speaking English. Participant three mentioned that he still felt nervous, though he prepared what he would say. The last non-observable symptom which was not listed in the observable checklist but it was mentioned by the participants is heart beating quickly. Participant one, participant two, and participant four mentioned that their heart pounded quickly when they spoke English.

\section{Discussions}

The study about the characteristics of anxious students is important to be researched because speaking anxiety is a big problem for the students who learn English. In addition, speaking anxiety needs to be overcome because speaking is a communication tool. The research was conducted in a private university in Yogyakarta, Indonesia where English is still a foreign language. Moreover, the students who were observed were English department students. Thus, this study gives information that speaking anxiety really exists even in English department. The instruments used by the researcher were observation and 
interview. By conducting observations, the researcher got live data. The researcher did the observations twice. The first observation was done when the students did group discussion, and the second observation was conducted when the students did the presentation in front of the classroom.

Based on the observation, the students were more anxious when they did the presentation in front of the classroom. It happened because the atmosphere in doing group discussion and presentation was different. When the students did a group discussion, they looked relaxed. A group consisted of five people. While sharing their opinions, sometimes they laughed with their friends, and they did not seem that they were anxious. Based on the researcher's opinion, the students did not seem anxious because they could ask their friends directly and easily when they got difficulty. On the other hand, when the students did a presentation in front of the class, they seem anxious though they did the presentation in pair. Some of the students trembled when they did a presentation in front of the classroom. Moreover, the students also showed other symptoms such as remaining silent and getting sweaty. Those symptoms are in line with Ansari (2015) who states that anxious students experience getting sweaty, trembling, remaining silent, and perspiring.
Additionally, some students also stuttered or stammered and touch object nervously. According to Suleimenova (2013), the characteristics shown by anxious students are "squirming, playing with hair or clothing, nervously touching objects, stuttering or stammering" (pp. 1861-1862). Besides observable symptoms, the researcher also found two non-observable symptoms. Those were getting confused and getting cold. According to Khan (2015), when a learner is supposed to speak English, s/he will be confused, nervous, and anxious. Moreover, Anandari explains that discomfort is the condition when the students "are uncomfortable with their bodies". Based on the data collection, those symptoms appeared more in the presentation than in group discussion. It can be said that the students were more anxious when they did public speaking such as presentation in front of the classroom.

After doing the observation, the researcher interviewed four students who showed more symptoms than the other students. From the interview, the researcher could know that the symptoms shown in the observations appeared because they were anxious. The symptoms in this research were divided into observable symptoms and nonobservable symptoms. The researcher confirmed that the observable symptoms 
appeared because of anxiety or not. However, some of the observable symptoms revealing in the observations appeared not because of the students' anxiety. For example, a participant touched object nervously when she did the presentation. She did that in order to reduce her anxiety. Additionally, two participants in this research avoided eye contact with the audience when they did the presentation. They did that to solve their speaking anxiety. In conclusion, the students showed the anxiety symptoms not because they were anxious, but they showed the symptoms in order to cope with their speaking anxiety. In addition, the non-observable symptoms were also found in this research because it was mentioned by the participants.

Based on the result of the observations and the interview, it can be concluded that the characteristics of anxious students can be divided into two which are observable symptoms and non-observable symptoms. In addition, from the observation done in two classrooms, it can be said that most of the students undergo speaking anxiety. However, the level of their anxiety is different from one student to the others, because the symptoms shown by the students are different. It supports the previous literature because the results are related. In addition, the results of this research adds information about the characteristics of anxious students, especially in speaking class.

\section{Conclusion and Implication}

According to the results of this research, speaking anxiety really exists in the EFL context. Higher education students even the English department students who learn English everyday experience speaking anxiety. It happens in a speaking activity such as group discussion and presentation. However, the students feel more anxious when they do public speaking. Therefore, it can be said that speaking anxiety really exists in a foreign language classroom.

After comparing the results of the observations and the interview, the observable symptoms appeared more than the non-observable symptoms. It indicates that it is not difficult to know if someone undergoes speaking anxiety. However, based on the interview, the participants showed the symptoms because they undergo speaking anxiety, and it is their way to solve their speaking anxiety. Thus, the observable symptoms appeared because the students were anxious and it can be their strategy to handle their anxiety. Finally, this study is beneficial for English teachers because the English teachers are able to identify which student is anxious in speaking. Moreover, 
the English teacher can find some strategies for the students to cope with speaking anxiety. The researcher also suggests the English teachers create a friendly classroom atmosphere, especially in a speaking class.

\section{References}

Aghani, M., \& Amanzadeh, H. (2017). The Effect of Anxiety on Speaking Ability: An Experimental Study on EFL Learners. Journal of Applied Linguistics and Language Research, 4(7), 154-164.

Ahmed, N. F. (2016). An exploration of speaking anxiety with Kurdish University EFL learners. Journal of Education and Practice, 7(27), 99-106. Retrieved from www.iiste.org

Ansari, M. S. (2015). Speaking anxiety in ESL/EFL classrooms: A holistic approach and practical study. International Journal of Educational Investigations, 2(4), 38-46. Retrieved from www.ijeionline.com

Awan, R.-u.-N., Azher, M., Anwar, M. N., \& $\mathrm{Naz}$, A. (2010). An Investigation of Foreign Language Classroom Anxiety and Its Relationship with Students' Achievement. Journal of College Teaching EB Learning, 7(11), 33-40.

Boyce, J. S., Alber-Morgan, S. R., \& Riley, J. G. (2007). Fearless public speaking: Oral presentation activities for the elementary classroom. Childhood Education, 83, 1-11.

Brown, H. D. (2000). Principles of Language Learning and Teaching. New York: Addison Wesley Longman, Inc.

Cohen, L., Manion, L., \& Marrison, K. (2011). Research methods in education. London: Routledge

Creswell, J. W. (2012). Educational research: Planning, conducting, and evaluating quantitative and qualitative research (4th ed.). Boston: Pearson
Dearden, J. (2014). English as a Medium of Instruction - a Growing Global

Phenomenon. Oxford: British Council.

Ibrahim, J. (2001). The implementation of EMI (English Medium Instruction) in

Indonesian Universities: Its opportunities, its threats, its problems, and its possible solutions. The 49th International TEFLIN Conference, 3(2), 121-138.

Lian, L. H., \& Budin, M. B. (2014). Investigating the Relationship between English Language Anxiety and the Achievement of School based Oral English Test among Malaysian Form Four Students. International Journal of Learning, Teaching, and Educational Research, 2(1), 67-79.

Liu, M. (2006). Anxiety in EFL Classroom: Causes and Consequences. TESL Reporter, 1(39), 13-32.

Mak, B. (2011). An exploration of speakingin-class anxiety with Chinese ESL learners. Science Direct, 202-214. doi:10.1016/j.system.2011.04.002

Marwan, A. (2008). The exploration of factors triggering foreign language anxiety: Learners' voice. TEFLIN Journal, 19(2), 119-126.

Merriam, S. B. (1998). Qualitative research and case study applications in education. San Fransisco: Jossey-Bass Publishers

Suleimenova, Z. (2013). Speaking anxiety in a foreign language classroom in Kazakhstan. Procedia-Social and Behavioral Sciences 93, 1860-1868. doi: 10.1016/j.sbspro.2013.10.131

Tsiplakides, I., \& Keramedina, A. (2009). Helping students overcome foreign language

speaking anxiety in the English classroom: Theoritical issues and practical recommendations. International Education Studies, 2(4), 39-44.

Wu, K. (2010). The relationship between language learners' anxiety and learning strategy in the CLT classroom. 
International Education Study, 3(1), 174191.

Yahya, M. (2013). Measuring speaking anxiety among speech communication source at Arab American University of
Jenin. European Social Science Research Journal, 1(3), 229-248.

Zheng, Y. (2008). Anxiety and second/foreign langauge learning. Canadian Journal.New Scholar Education, 1(1), 1-12. 